\title{
Nanocomposite Melt Spun PET fibers for Environmental Remediation
}

\author{
Raedah A. S. Alatawi \\ Department of Chemistry, Faculty of Science, University of Tabuk, Tabuk, 71421, \\ Saudia Arabia
}

\begin{abstract}
$\mathbf{P}$ OLYETHYLENE terphthalate /Montmorillonite clay nanocomposites were prepared after modification of Montmorillonite (MMT) clay using different concentration of Dimethyl di(hydrogenated tallow) ammonium chloride modifier. The characterization of the prepared nanocomposites includes Fourier-transform infrared (FTIR), thermal gravimetric analysis (TGA) and scanning electron microscope (SEM). Fibers of pure polyethylene terphthalate (PET) and Polyethylene terphthalate/Montmorillonite clay nanocomposite (PET/MMT) were produced using melt spinning technique and the prepared fibers were characterized using thermal gravimetric in addition to SEM analysis. The results show that the nanocomposite fibers have higher thermal stability than pure polyethylene terphthalate fibers in addition to high degree in homogeneity between PET and MMT clay in PET/MMT nanocomposite. PET/ MMT nanocomposite fiber with modified MMT $2 \%$ has been modified by grafting of MAA under variable conditions of monomer and initiator concentrations as well as grafting time and temperature. The grafted fiber has been used in water treatment by removing of cationic dye under different conditions as $\mathrm{pH}$ values, and dye adsorption time.
\end{abstract}

Keywords: Polyethylene terphthalate; Montmorillonite; Melt Spinning; Grafting; Dye removal

\section{Introduction}

Poly(ethylene terephthalate), or PET, is a thermoplastic polyester resin produced commercially from ethylene glycol (EG) and either dimethyl terephthalate (DMT) or terephthalic acid (TPA). Such resins may be classified as low-viscosity or high-viscosity resins according to the intrinsic viscosity value [1-2]. PET is used extensively in the manufacture of synthetic fibers which compose the largest segment of the synthetic fiber industry [3-5]. Introducing small amounts of Nano clays into the PET polymer matrix is one of the passive barrier methods used to further improve thermal stability, barrier, and mechanical properties of PET [6]. These improvements, however, are greatly influenced by the degree of clay dispersion into the polymer matrix [7]. Pristine montmorillonite (MMT) and commercially modified clays have been widely used in areas of nanocomposite research [8].

The first man-made fiber, known as viscose rayon, was invented by French scientist and industrialist Hilaire de Chardonnet in 1891. Since then, synthetic fibers have been largely used in the textile industry for apparel applications and as reinforcement for composite plastics [9]. In this process polymer granules are melted and molten polymer is extruded through spinnerets. The continuous filaments are cooled and deposited on to a conveyor to form a uniform web. The formation of a web of continuous filaments deposited on the conveyor belt is assisted by suction [10]. The coating of textile surfaces by another polymer via grafting process is an interesting way for the approach confers to textile surfaces other properties such as impermeability to water or gases and adsorption of dyed and heavy metals [1112]. The aim of this work is to prepare polyethylene terphthalate / montmorillonite nanocomposite filament yearns via melt extrusion process and modifying the produced nanocomposite filaments by grafting of methacrylic acid for using in dye removal from water samples

\section{Experimental details}

Materials

Montmorillonite clay (MMT) with cation exchange capacity (CEC) 100 meq per $100 \mathrm{~g}$ was supplied by Süd-Chemie - Moosburg -Germany.

*E-mail:;r.alatawi@ut.edu.sa; raedahalatawi@gmail.com

DOI: $10.21608 /$ jtcps.2020.25103.1035

Recevied 3/3/2020, Accepted 9/3/2020

(C)2020 National Information and Documentation Centre (NIDOC) 
The modifier Dimethyl di (hydrogenated tallow) ammonium chloride was supplied from Sigma -Aldrich - Steinheim - Germany.

Commercial homopolymer polyethylene terphthalate PET granules were provided by SABIC, KSA. The PET-HC100 is characterized by an intrinsic viscosity (IV) of $0.84 \mathrm{Dl} / \mathrm{g}$, melting range between 240 and $260{ }^{\circ} \mathrm{C}$ and a crystalline density $<1400 \mathrm{~kg} / \mathrm{m} 3$. The dye used is reactive blue 19 (Figure 1) supplied from Merck - Darmstadt - Germany, its molecular structure $\mathrm{C}_{22} \mathrm{H}_{16} \mathrm{~N}_{2} \mathrm{Na}_{2} \mathrm{O}_{11} \mathrm{~S}_{3}$ and molecular weight 626.55. Methacrylic acid (MAA) $\mathrm{CH}_{2}=\mathrm{C}\left(\mathrm{CH}_{3}\right)$ $\mathrm{COOH}$ is the monomer used for grafting supplied from Merck - Darmstadt - Germany. Azobisisobutyronitrile (AIBN) initiator supplied from Across company - Germany.

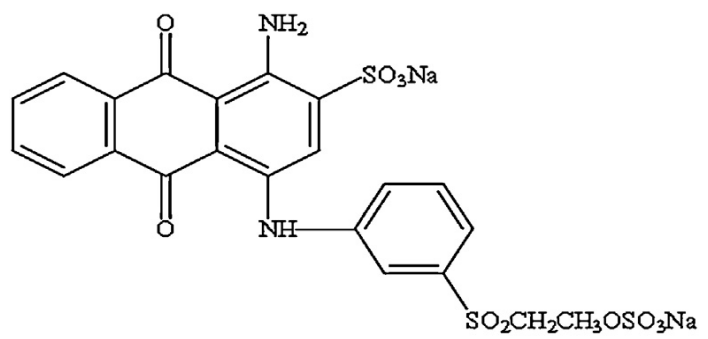
reactive blue 19

Fig. 1. Structure of Reactive Blue 19.

Methods

Intercalated Modification of MMT with Dimethyl di(hydrogenated tallow) ammonium chloride [13]:

MMT was first swollen in $100 \mathrm{ml}$ distilled water by magnetic stirring in room temperature for an hour and then different percentage (1:3\%) of Dimethyl di(hydrogenated tallow) ammonium chloride (Figure 2) was added to it, followed by mechanical stirring 4 hours at $80 \mathrm{oC}$ on water path connected with condenser. Then, Tallow/MMT mixtures were filtered and dried under vacuum at $70{ }^{\circ} \mathrm{C}$ for 48 hours.<smiles>CCC(C)(C)CC(=O)OC(OC(=O)CC(C)(C)C)=[N+](C)C</smiles>

Fig. 2. Dimethyl di(hydrogenated tallow) ammonium chloride.

Preparation of PET/MMT masterbatches [14]:

PET granules and tallow modified organoclay, was initially dried and stored in air tight vessels until usage to avoid degradation of PET J. Text. Color. Polym. Sci. 17, No. 1 (2020) polymer during extrusion. For compounding, the MMT powder and PET polymer was premixed in quantities of $0.5,1$ and 2 wt. \% modified MMT content. The mixtures were extruded as polymer strands using a HAAKE twin screw extruder, cooled in a water bath and pelletized. The granulate was dried and stored in air tight vessels until further usage. The conditions of preparing MMT- Tallow are shown in Table1.

TABLE 1. Conditions of preparing PET/Tallow modified MMT.

\begin{tabular}{|c|c|c|c|}
\hline Sample & Temperature & \multicolumn{2}{|c|}{ Extruder parameters } \\
\hline Zone $1 /{ }^{\circ} \mathrm{C}$ & 283 & $\begin{array}{c}\text { Rotation speed } \\
/ \mathrm{rpm}\end{array}$ & 100 \\
\hline Zone $2 /{ }^{\circ} \mathrm{C}$ & 288 & Pressure $/ \mathrm{bar}$ & $10-8$ \\
\hline Zone $3 /{ }^{\circ} \mathrm{C}$ & 289 & Torque $/ \mathrm{Nm}$ & $50-70$ \\
\hline Zone $4 /{ }^{\circ} \mathrm{C}$ & 289 & - & - \\
\hline Nozzle $/{ }^{\circ} \mathrm{C}$ & 295 & - & - \\
\hline $\begin{array}{c}\text { Polymer } \\
\text { melt } /{ }^{\circ} \mathrm{C}\end{array}$ & $309 / 306$ & - & - \\
\hline
\end{tabular}

Spinning of PET/MMT filaments [15]:

In order to prepare nanocomposite fiber, the prepared PET/MMT with $2 \%$ tallow modified MMT clay content was dried at $90^{\circ} \mathrm{C}$ for 24 hours in a vacuum oven (Table 2), and in order to be on the safe side, water content of samples measured according Karl Fischer method (ASTM E203-08) [16]. Fiber melt spinning was carried out using a spinning apparatus (HAAKE single screw extruder) consisting of an extruder and a gear pump to control precisely the throughput rate, which was kept at $40 \mathrm{~g} / \mathrm{min}$ for all polymers. Filaments extruded through a 24-hole spinneret with a diameter of $0.3 \mathrm{~mm}$ and at $275^{\circ} \mathrm{C}$ were taken up by the high-speed winder SW46 of BARMAG Company below the spinneret.

TABLE 2. Melt-Spinning conditions of PET/Tallow modified MMT.

\begin{tabular}{|c|c|c|}
\hline Temperature & PET & PET/Tallow \\
\hline Zone $1{ }^{\circ} \mathrm{C}$ & 280 & 280 \\
\hline Zone $2{ }^{\circ} \mathrm{C}$ & 280 & 287 \\
\hline Zone $3{ }^{\circ} \mathrm{C}$ & 285 & 287 \\
\hline Pump ${ }^{\circ} \mathrm{C}$ & 290 & 284 \\
\hline Spinneret ${ }^{\circ} \mathrm{C}$ & 289 & 282 \\
\hline Melt $/{ }^{\circ} \mathrm{C}$ & 292 & 287 \\
\hline Spinneret & - & - \\
\hline Pressure $/ \mathrm{bar}$ & 42 & 50 \\
\hline Winding speed & - & - \\
\hline Winder $/ \mathrm{m} / \mathrm{min}$ & 3000 & 2000 \\
\hline
\end{tabular}


Grafting of MAA onto the produced PETMMT fiber [17].

The desired amount of PET-MMT fiber was placed in a $100 \mathrm{ml}$ polymerization tube containing the required concentration of MAA monomer and AIBN initiator in $10 \mathrm{ml}$ acetone. The volume of the polymerization mixture was made up to 50 $\mathrm{ml}$ with distilled water, and then the mixture was immediately placed into a water bath at $80^{\circ} \mathrm{C}$. After the desired polymerization time (30-180 min.), the fiber samples were taken out of the tube and washed with water and soxhlet extracted with acetone for $4 \mathrm{~h}$. Finally, the samples were dried. Grafting yield is calculated according to the following equation:

Grafting yield $(\%)=\left[\left(\mathrm{W}_{\mathrm{g}}-\mathrm{W}_{\mathrm{o}}\right) / \mathrm{W}_{\mathrm{o}}\right] \times 100$

where $\mathrm{W}_{\mathrm{o}}$ and $\mathrm{W}_{\mathrm{g}}$ denote the weights of the original and grafted PET, respectively.

Using the modified PET-MMT filaments in adsorption of cationic dye [18]:

The effect of $\mathrm{pH}$ value, adsorption time, concentration of cationic dye will be the factors used to study the adsorption performance of the prepared PET-MMT nanocomposite fibers in adsorption of RB 19 dye from environmental water samples as follow:

The effect of $\mathrm{pH}$ on the amount of the dye removal will be analyzed over the $\mathrm{pH}$ range from 8 to 12 , which will be adjusted by $1 \mathrm{~N} \mathrm{NaOH}$ solution. A $20 \mathrm{~mL}$ of the dye solutions $(20 \mathrm{mg} / \mathrm{L})$ and different amount of nanofibers adsorbent will be mixed in a flask. The flasks will be agitated for different times under different temperature oscillator operated at $150 \mathrm{rpm}$. For the kinetic studies, 0.3 gram of the adsorbent was added to $50 \mathrm{ml}$ dye solution. The initial concentrations of the dye solutions were 50 , 100,150 and $200 \mathrm{mg} / \mathrm{l}$, and the experiments were carried out at $30,35,40$ and $45^{\circ} \mathrm{C}$, respectively. The treated samples will be then collected and centrifuged at different time intervals. The remaining concentrations of the dye in the solutions after adsorption will be analyzed and measured as before.
The data obtained in batch mode studies will be used to calculate the equilibrium dye adsorption quantities. It was calculated for adsorptive quantity of the dye by using the following expressions:

$\%$ Removal $=(\mathrm{C} 0-\mathrm{Ce}) / \mathrm{C} 0 \times 100 \%$

where $\mathrm{C}_{0}$ in $\mathrm{mg} / \mathrm{L}$, is representing the initial concentration of dye solution, and, $\mathrm{C}_{\mathrm{e}}$ in $\mathrm{mg} / \mathrm{L}$ represents the equilibrium concentration of dye in the aqueous solution.

\section{Characterization}

X-ray diffraction (XRD) measurements were performed using a Philips powder-diffractogram PW 1050 with ADM software and with Nifiltered $\mathrm{Cu}-\mathrm{K}$ radiation. The accelerating voltage was $40 \mathrm{KV}$, and the current was $30 \mathrm{~mA}$. The morphology and fracture surface of the polymer and its composite were examined by scanning electron microscope (SEM) analysis using a Zeiss DSM 962 microscope. Thermogravimetric analysis (TGA) was determined on a TGA 7 thermogravimetric analyzer (Perkin Elmer) under a nitrogen flow at a heating rate of $10^{\circ} \mathrm{C} \mathrm{min}^{-1}$. The Fourier transfer infrared (FTIR) spectra were obtained using a Bruker IFS 28 spectrometer 67. The residual concentration of the dye in the solution will be analyzed and measured using Perkin Elmer UV-Vis Spectrophotometer at its maximum absorption wavelength $(592 \mathrm{~nm})$.

\section{Results and discussions}

Modification of MMT clay

$X$-Ray Diffraction (XRD)

Figure 3 shows the XRD diffractograms of Pure and organo-modified MMT by the addition of Dimethyl di (hydrogenated tallow) ammonium chloride modifier at different percentages $(1 \%$, $2 \%$, and $3 \%$ ). illustrates X-ray diffraction for pristine MMT clay and its intercalated modified MMT using. The interlayer spacing $\left(\mathrm{d}_{001}\right)$ value of the pristine and modified MMT are calculated via Bragg's equation [19]:

$$
\mathrm{n} \lambda=2 \mathrm{~d} \sin \theta
$$

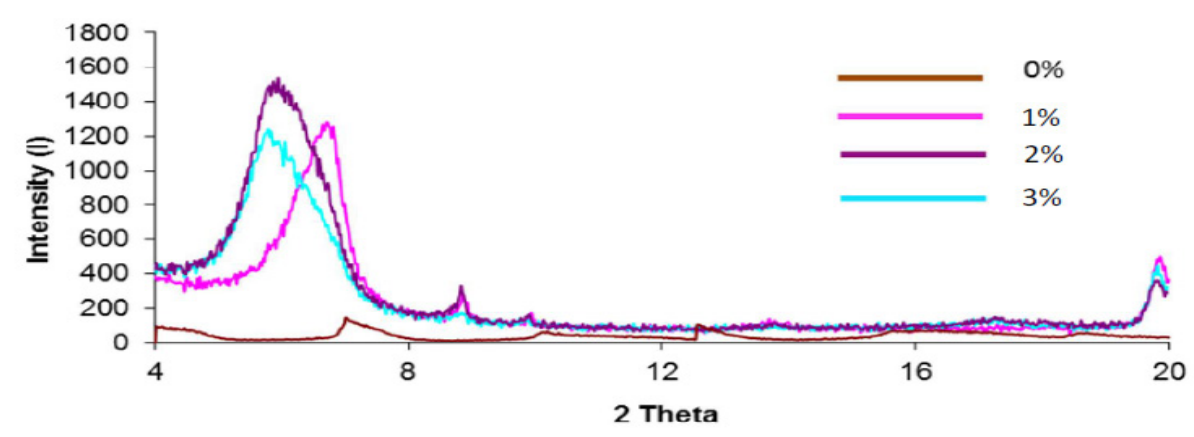

Fig. 3. XRD patterns of organic modification of MMT clay.

J. Text. Color. Polym. Sci. 17, No. 1 (2020) 
The data illustrated indicate pure MMT has a diffraction peak at $2 \Theta=6.99^{\circ}$, corresponding to a basal spacing of $11.73 \mathrm{~nm}$. The modified clay have greater basal spacing due to intercalation, revealed by the diffraction peak shifted to $2 \Theta=$ $6.71^{\circ}$ for $1 \%$ addition of Tallow, $2 \Theta=5.97^{\circ}$ for $2 \%$ addition and $2 \Theta=5.95^{\circ}$ for $3 \%$ addition, which correspond to the basal spacing of 12.22 $\mathrm{nm}, 13.78 \mathrm{~nm}$ and $14.16 \mathrm{~nm}$, respectively? The highest basal spacing of $14.16 \mathrm{~nm}\left(2 \Theta=5.95^{\circ}\right)$ was obtained for $3 \%$ addition of Tallow to the MMT as shown in (Table 3).

TABLE 3. Modification of MMT clay using Dimethyl di (hydrogenated tallow) ammonium chloride.

\begin{tabular}{|c|c|c|}
\hline Organoclay & $\mathbf{2 \theta}\left(^{\circ}\right)$ & $\begin{array}{c}\text { Basal spacing } \\
(\mathbf{n m})\end{array}$ \\
\hline Pure MMT & 6.99 & 11.73 \\
\hline MMT+1\%Tallow & 6.71 & 12.22 \\
\hline MMT+2\%Tallow & 5.79 & 13.78 \\
\hline MMT+3\%Tallow & 5.95 & 14.16 \\
\hline
\end{tabular}

\section{Scanning Electron Microscope (SEM)}

The morphology investigation of the pristine MMT and tallow-modified MMT has been investigated by using SEM as present in Figure 4. It is clear that, Pristine MMT clay has a poor dispersion in the solvent and some agglomerations have been observed, while tallow modified MMT clay was uniformly distributed with regular dispersion due to a compelling organophilic change accompanied by clay modifications [20].

Structure and properties of PET and PET/MMT nanocomposite

\section{Scanning Electron Microscope (SEM)}

In order to confirm the XRD results, the morphology of pure PET and PET/MMT nanocomposite were investigated by SEM as presented in Figure 5. From the SEM observations at the high magnification, the modified MMT nanoparticles is uniformly distributed without agglomeration within the polymer matrix.

A
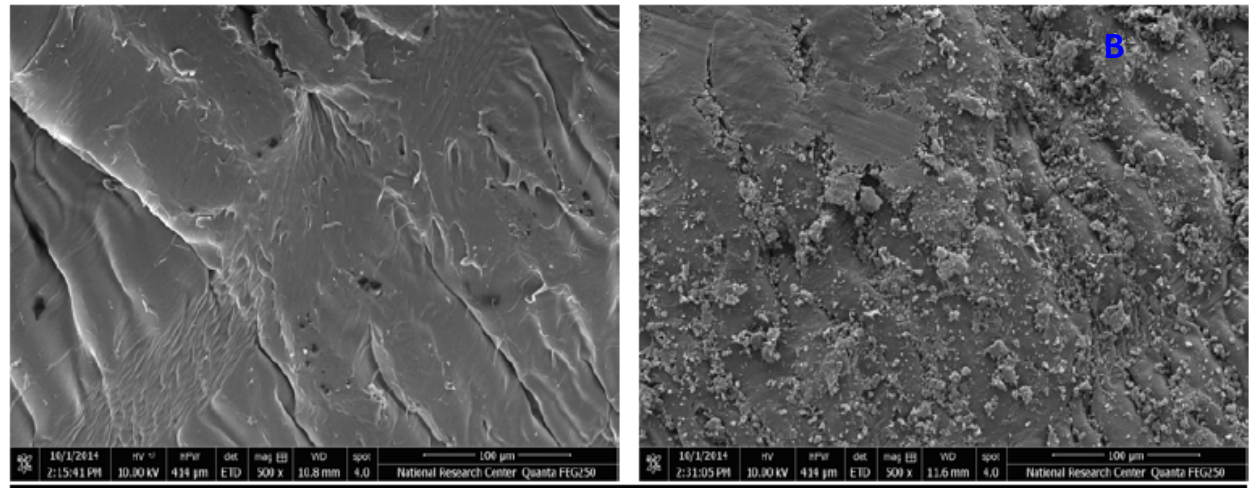

Fig. 4. Scanning electron microscopy of (a) MMT clay and (b) Organomodified MMT clay.
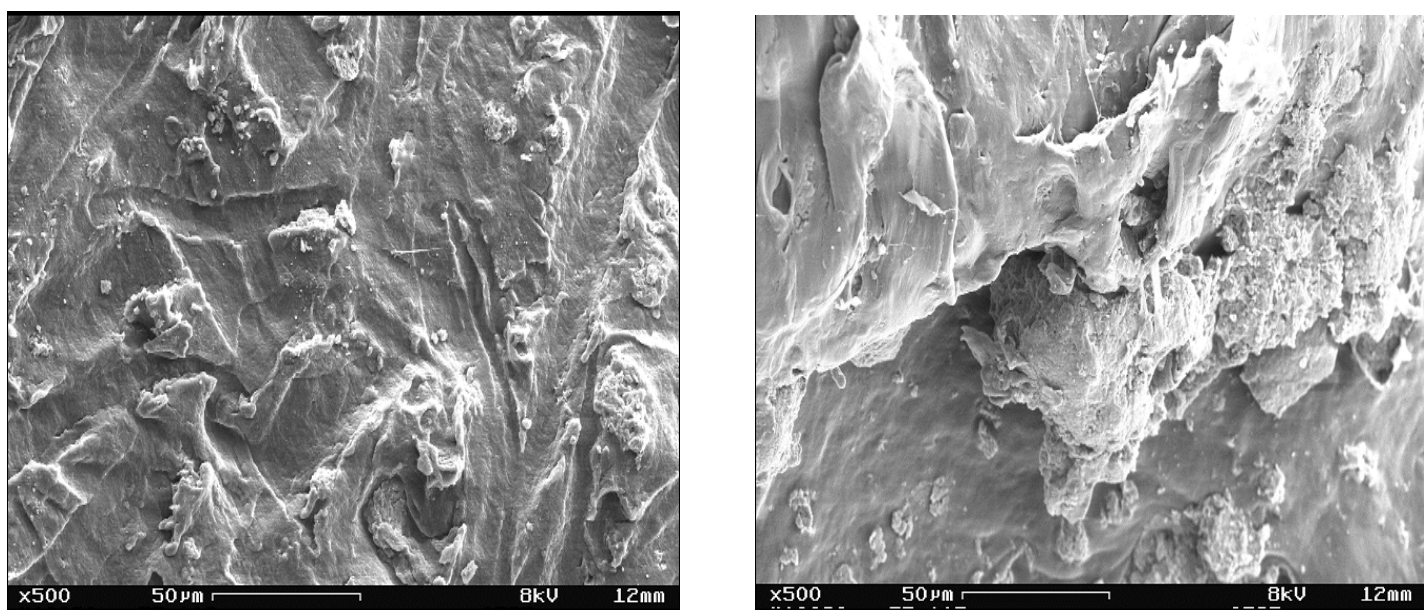

Fig. 5. SEM of (left) pure PET and (right) organoclay/PET nanocomposite.

J. Text. Color. Polym. Sci. 17, No. 1 (2020) 
Infra-red analysis (FT-IR)

Figure 6 displays the FTIR of modified MMT, pure PET and PET/MMT nanocomposite. It is clear that, the successfully intercalation of the MMT clay in the preparation of PET / MMT nanocomposite has been confirmed by the presence of the characteristic absorption peak of Si-O group at $1092 \mathrm{~cm}^{-1}$ in the both MMT and PET/MMT nanocomposite analysis[21].

Thermal Gravimetric Analysis

Thermal gravimetric analysis (TGA) for both pure PET and PET/MMT nanocomposite with different modified MMT contents within temperature range between $50-600^{\circ} \mathrm{C}$ is represented in Figure 7. This figure is used in determining of the following temperatures, i) the fiber starting degradation temperature $\left(\mathrm{T}_{\text {start }}\right)$, ii) the temperature in which the fiber loses $25 \%$ of its weight $\left(\mathrm{T}_{25}\right)$, iii) the temperature in which the fiber loses $50 \%$ of its weight $\left(\mathrm{T}_{50}\right)$ and iv) the temperature in which the fiber loses $75 \%$ of its weight $\left(T_{75}\right)$. The determined temperatures are listed in Table 4 . The data illustrated in this table refers to important role played by of the modified MMT clay in the enhancement of thermal stability for the produced PET polymer, this result can be attributed to the motion limitation of MMT clay layers .
TABLE 4. TGA data for pure PET and PET/MMT nanocomposite

\begin{tabular}{|c|c|c|c|c|}
\hline \multirow{2}{*}{ Temperature } & \multirow{2}{*}{$\begin{array}{c}\text { Pure } \\
\text { PET }\end{array}$} & \multicolumn{3}{|c|}{ PE/modified MMT } \\
\cline { 3 - 5 } & & $\mathbf{0 . 5 \%}$ & $\mathbf{1 \%}$ & $\begin{array}{c}\mathbf{2 \%} \\
\text { MMT }\end{array}$ \\
MMT & MMT \\
\hline $\mathrm{T}_{\text {Start }}$ & 276 & 293 & 302 & 314 \\
$\mathrm{~T}_{25}$ & 351 & 369 & 400 & 406 \\
$\mathrm{~T}_{50}$ & 389 & 404 & 425 & 436 \\
$\mathrm{~T}_{75}$ & 411 & 429 & 443 & 462 \\
\hline
\end{tabular}

Polyethylene terphthalate / Montmorillonite Fiber Production and modification by grafting of MAA monomer

PET/MMT nanocomposite with $2 \%$ tallow modified MMT clay was carried out using a spinning apparatus and the produced filament yearns have been modified by grafting yield of MAA monomer using AIBN initiator under several grafting variable conditions where grafting yield percentage has been calculated for all factors studied which affecting the grafting process to determine the optimum yield using the following equation [18].

$$
\text { Grafting yield }(\%)=\left[\left(\mathrm{W}_{\mathrm{g}}-\mathrm{W}_{\mathrm{o}}\right) / \mathrm{W}_{\mathrm{o}}\right] \times 100
$$

$\mathrm{W}_{\mathrm{o}}$ and $\mathrm{W}_{\mathrm{g}}$ represent fiber weight before and after grafting process.

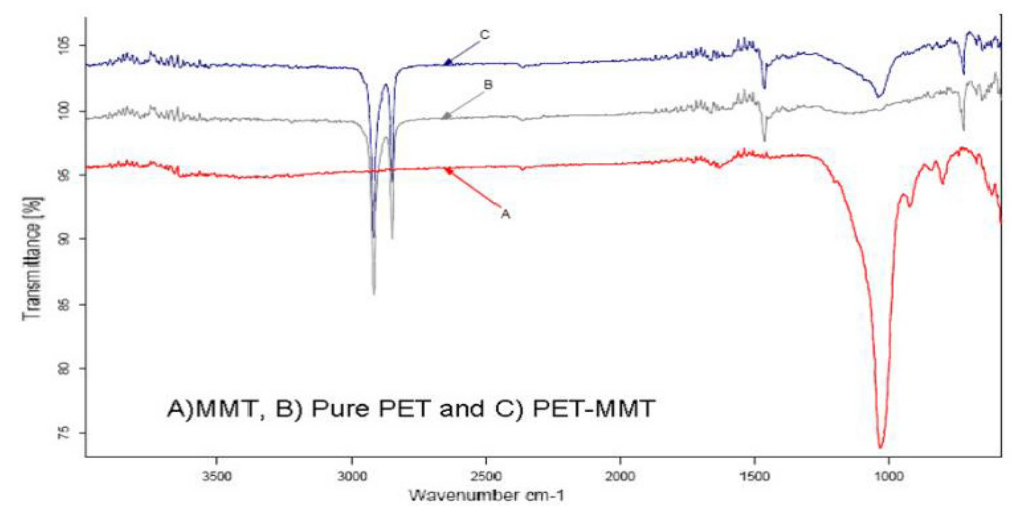

Fig. 6. FTIR spectrum of A) Modified-MMT, B) Pure PET and C) PET/ MMT nanocomposite.

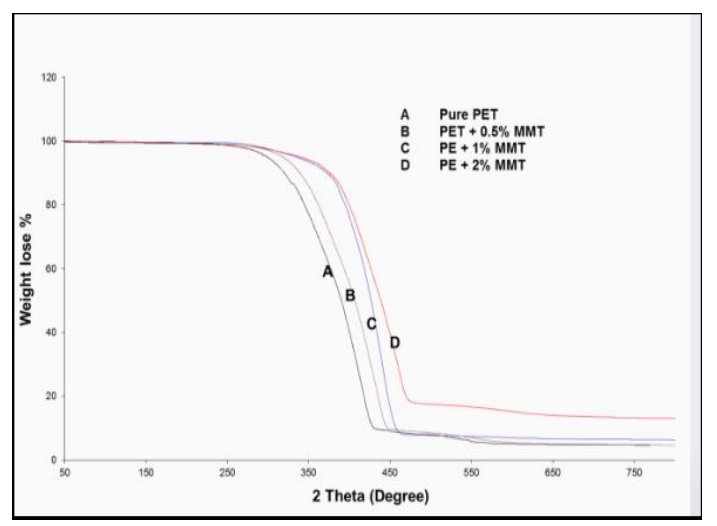

Fig. 7. TGA thermograms of pure PET and the PET/MMT nanocomposites. 
The effect of monomer concentration and initiator amount as well as the effect of grafting time on the grafting yield of MAA monomer onto PET/MMT nanocomposite filaments have been studied using monomer concentration range from $0.5: 5 \%$ from fiber weight and initiator concentration range from $1 * 10^{-2}: 5^{*} 10^{-2} \mathrm{gm}$ where the grafting process was carried out under $80^{\circ} \mathrm{C}$ within the grafting time $30: 180 \mathrm{~min}$ and the results are illustrated in Figure 8.

\section{Effect of monomer concentration}

Figure 9 illustrates monomer concentrations effect in the range $0.5: 5 \%$ on grafting yield at $3 * 10^{-}$ ${ }^{2}$ gm constant initiator concentration and one hour grafting time. It is clear that, the grafting yield increased by increasing monomer concentration till monomer concentration 3\% and then the grafting yield starts to decrease. The direct relationship between the grafting yield and the monomer concentration can be attributed to the high availability of polymer chains at high monomer concentration. The decreasing of grafting yield after
$3 \%$ monomer concentration could be attributed to decreasing of monomer penetration onto filaments due to increasing of solution viscosity at high monomer concentration [22].

\section{Effect of initiator amount}

Figure 10 illustrated the initiator concentration effect in the range $1 * 10^{-2}: 5^{*} 10^{-2}$ gm on the grafting yield at $3 \%$ constant monomer concentration and one hour grafting time. From this figure, the grafting percentage increased with initiator concentration till $4 * 10^{-2} \mathrm{gm}$ and then the grafting yield starts to decrease. The increasing of grafting percentage by increasing the concentration of initiator can be attributed to, at high initiator concentration, a high number of active sites suitable for growing polymer chains was available. The decreasing of grafting yield after $4 * 10^{-2}$ gm initiator may have been because, when the concentration of the initiator increased, the number of available free radicals will also increased which led to termination of the growing polymer chains and decreasing of the grafting percentage [23].

Fig. 8.

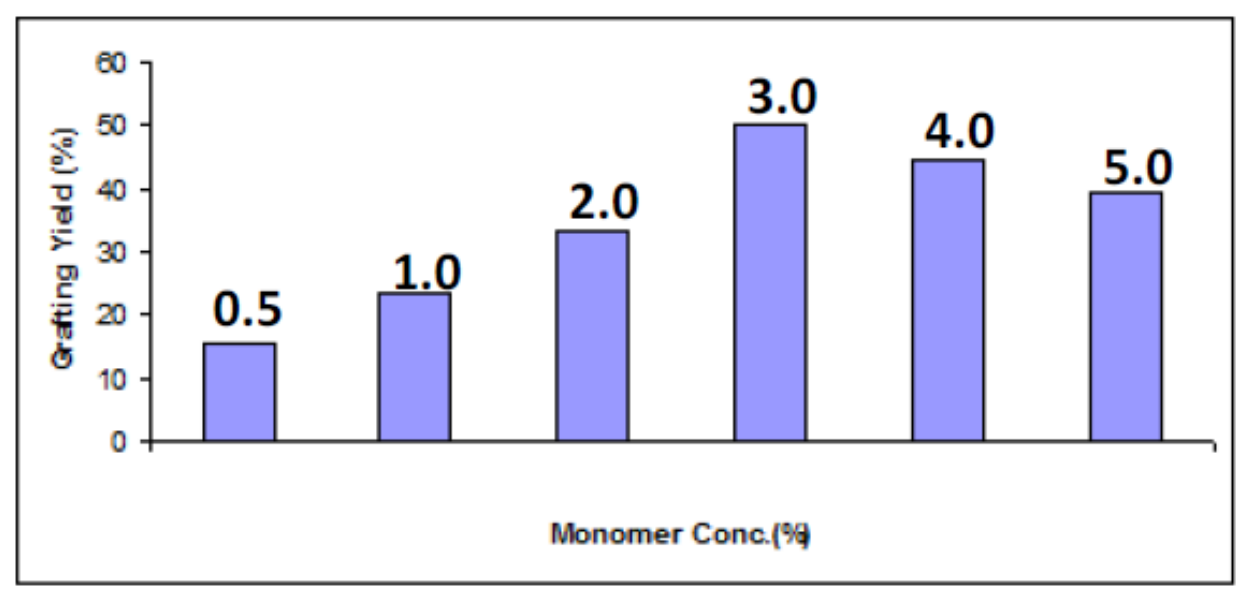

Fig. 9. Effect of monomer concentration on the grafting yield \%. 


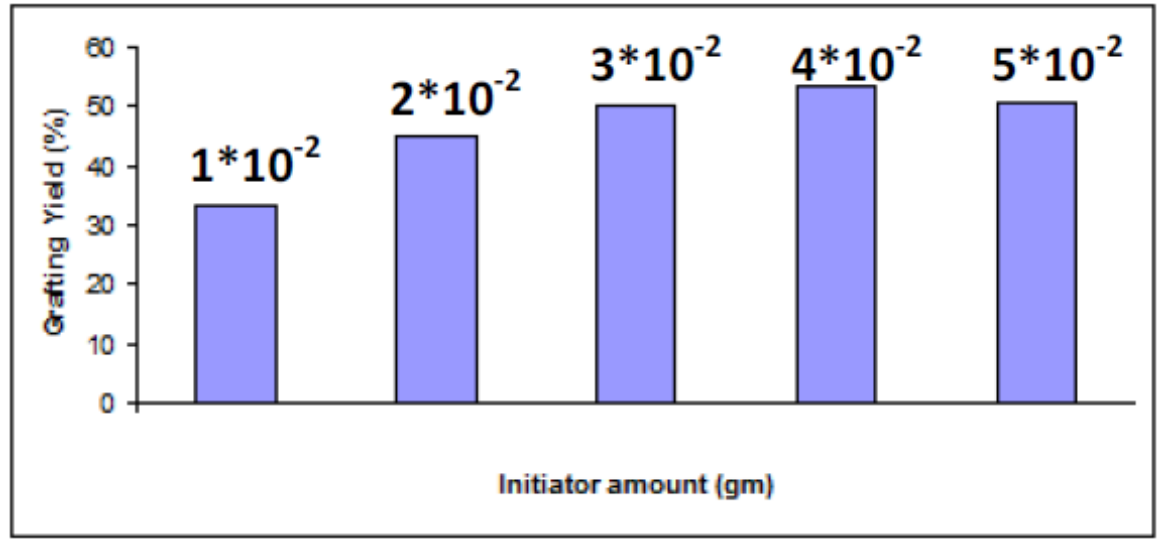

Fig. 10. Effect of initiator amount on the grafting yield \%.

\section{Effect of grafting time}

Figure 11 illustrates grafting time effect in range $30: 180 \mathrm{~min}$ on the grafting percentage under monomer concentration $3 \%$ and $3 * 10^{-2} \mathrm{gm}$ constant initiator concentration. It is clear that, the grafting yield percentage increased rapidly in the first $90 \mathrm{~min}$ and then tended to be fixed, This phenomena could be due to the decreasing of monomer and initiator concentrations and changes in the components of the system as the reaction proceeded.

Characterization of Polyethylene terphthalate / Montmorillonite Fiber

Scanning Electron Microscope (SEM)

Figure 12 shows the scanning electron microscope of pure PET, PET/MMT and PET/ MMT-grafted MAA. The pure PET filaments are totally isolated from each other, Also some aggregates of MMT clay can be noticed on PET/ MMT filaments where in case of MAA grafted fiber, bundles of fibers have been formed due to the grafting polymerization process [24].

Infra-red analysis (FT-IR)

Figure 13 shows FTIR of MMT/PET grafted with MAA. The peak at $1727 \mathrm{~cm}-1$ corresponds to the stretch vibration of $-\mathrm{COOH}$ group which proves that grafting occurred [21].

Application of Grafted Polyethylene terphthalate / Montmorillonite Fiber in Dye Removing

The ability of the grafted modified nanocomposite filament (PET/MMT - grafted MAA) to adsorb RB19 cationic dye from its solution has been studied and removal \% was calculated under several adsorption conditions as follow:

\section{Effect of pH on Cationic Dye Adsorption}

The effect of $\mathrm{pH}$ on the ability of PET/MMTg - MAA for adsorption of RB19 cationic dye at varying $\mathrm{pH}(\mathrm{pH} 8: 12$ ) with $50 \mathrm{mg} / 1$ fixed initial dye concentration and adsorbent dosage $10 \mathrm{~g} / 1$ for 120 min under temperature $30^{\circ} \mathrm{C}$ has been listed in Table 5 and illustrated in Figure 14. It can be concluded that the adsorption of a cationic dye onto PET-MMT- $g$ - MAA is strongly dependent on the $\mathrm{pH}$ of solution where there is a directly relationship between the dye adsorption capacity and $\mathrm{pH}$ value in the range of $\mathrm{pH} 8$ to 12 . The maximum adsorption capacity of the PE-MMT- $g$ - MAA was $86 \%$ of the dye removed at $\mathrm{pH}$ from 10 to 12 .

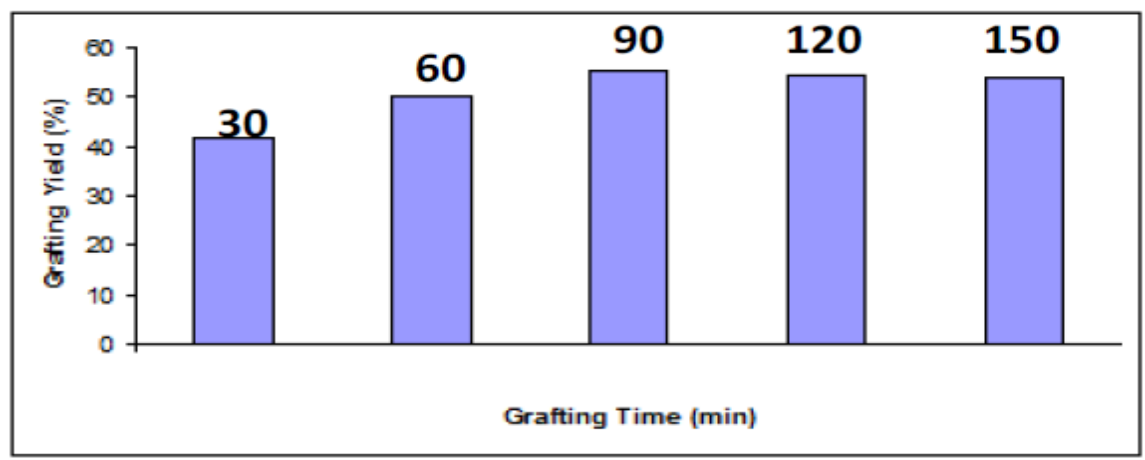

Fig. 11. Effect of grafting time on the grafting yield \%. 

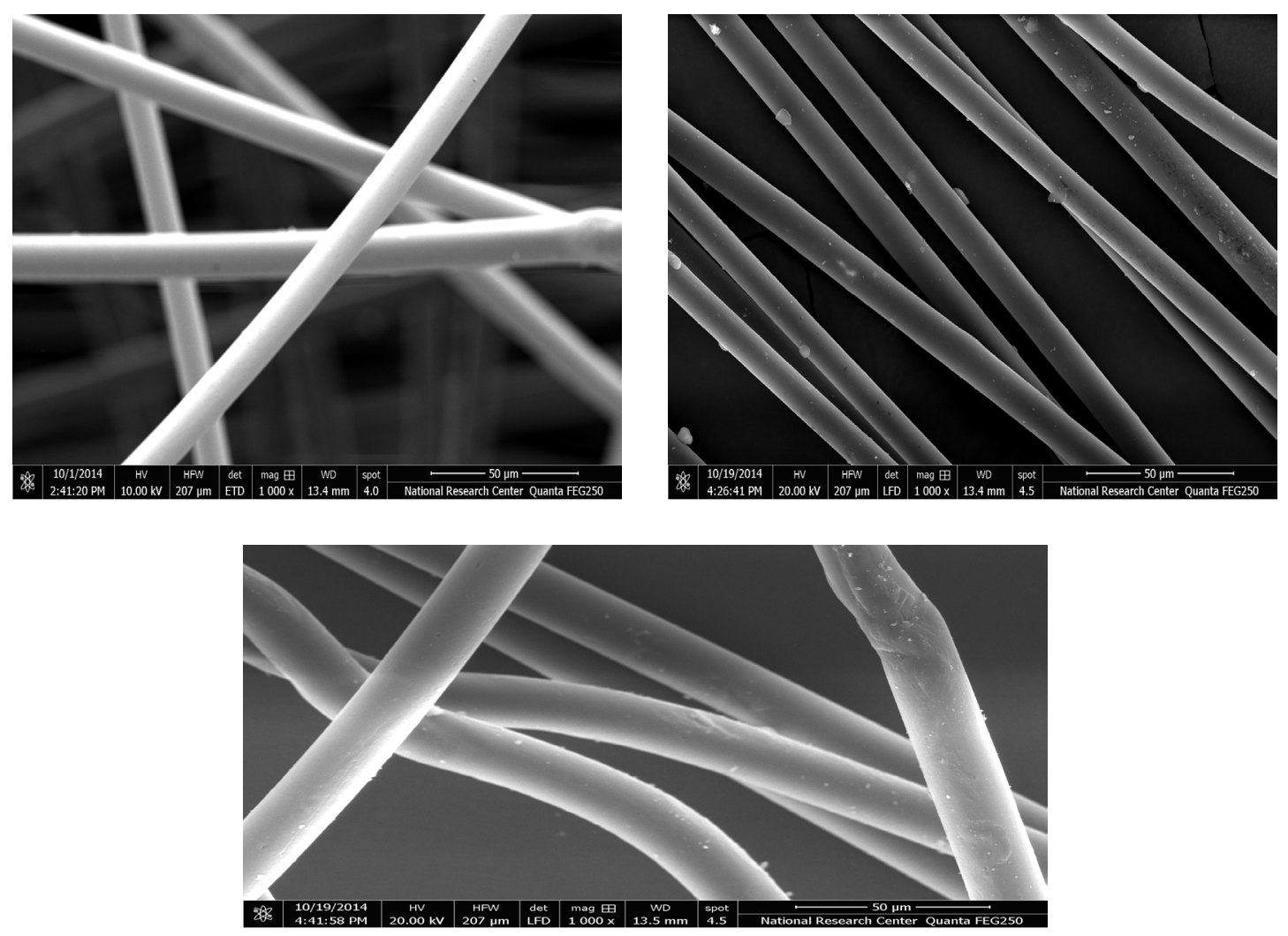

Fig. 12. SEM images for A) Pure PET, B) PET/MMT and C) PET/MMT-grafted MAA

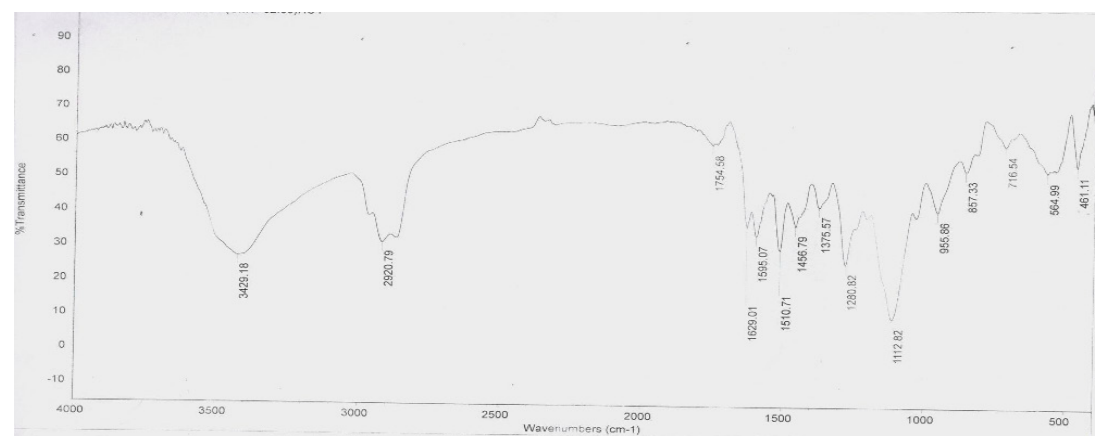

Fig. 13. FT-IR for PET/MMT-grafted MAA.

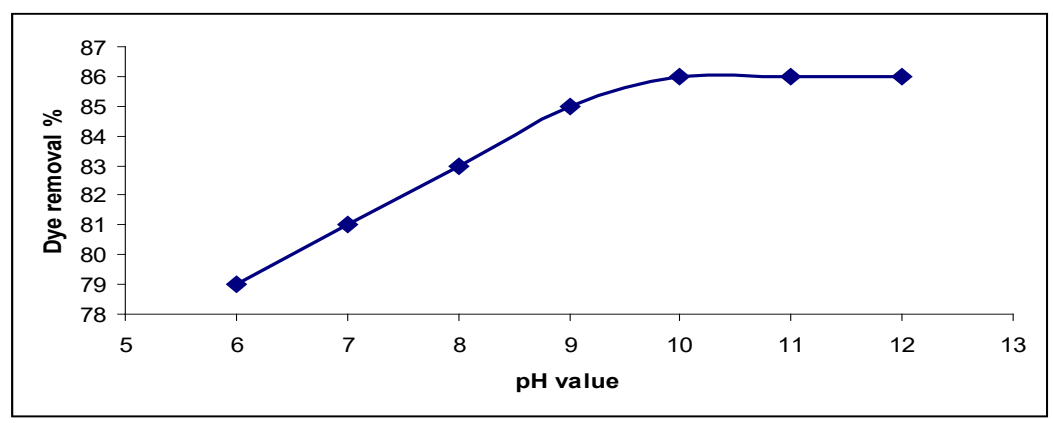

Fig. 14. Effect of $\mathrm{pH}$ value on the cationic dye removal $\%$. 
TABLE 5. Effect of $\mathrm{pH}$ value on the cationic dye adsorption

\begin{tabular}{|c|c|}
\hline $\mathbf{p H}-$-values & Dye removal \% \\
\hline 6 & 79 \\
7 & 81 \\
8 & 83 \\
9 & 85 \\
10 & 86 \\
11 & 86 \\
12 & 86 \\
\hline
\end{tabular}

Effect of temperature on cationic dye adsorption

$\mathrm{pH} 10$, time 120 minutes, temperature (30$45^{\circ} \mathrm{C}$ ), $150 \mathrm{rpm}$, Adsorption dose $10 \mathrm{~g} / \mathrm{l}$, Dye conc. $50 \mathrm{mg} / \mathrm{l}$. Dye removal increased with increasing the temperature due to the increasing of the clay surface penetration rate at high temperature as indicated in Table 6 and Figure 15.

TABLE 6. Effect of temperature value on the cationic dye adsorption

\begin{tabular}{|c|c|}
\hline Temperature & Dye removal \% \\
\hline 30 & 86 \\
35 & 89 \\
40 & 90 \\
45 & 90 \\
\hline
\end{tabular}

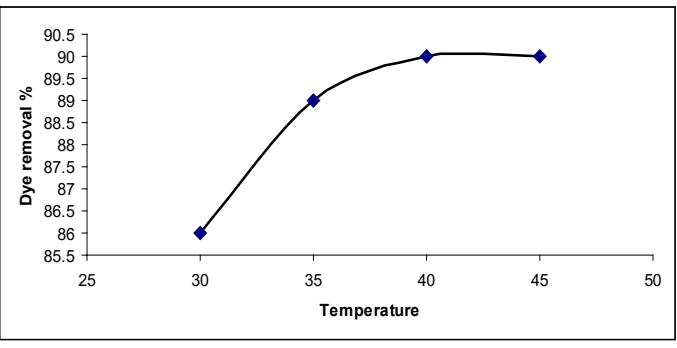

Fig. 15. Effect of temperature on the cationic dye removal \%.

Effect of dye concentration on cationic dye adsorption

At $\mathrm{pH} 10$, time $120 \mathrm{~min}$, temp. $30^{\circ} \mathrm{C}, 150 \mathrm{rpm}$, Adsorption dose $10 \mathrm{~g} / \mathrm{l}$, Dye conc. (50 -200) mg/l. Initial dye concentration plays an important role to defeat the mass exchange obstruction of the dye between the aqueous and the solid phases [24]. The adsorption of dye on adsorbent was studied by varying the concentration of initial dye from 50 to $200 \mathrm{mg} \mathrm{L}^{-1}$. It was observed that there is an inversely relationship between the initial dye concentration and the percentage of dye (Table 7 and Figure 16).
TABLE 7. Effect of dye concentration on the cationic dye adsorption

\begin{tabular}{|c|c|}
\hline Dye conc. & Dye removal \% \\
\hline 50 & 86 \\
100 & 81 \\
150 & 64 \\
200 & 49 \\
\hline
\end{tabular}

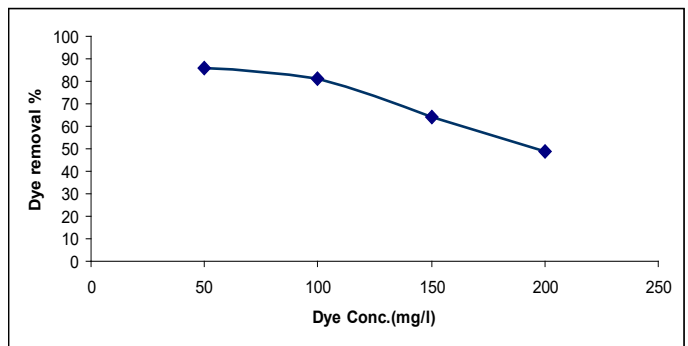

Fig. 16. Effect of cationic dye concentration on the cationic dye removal \%.

\section{Conclusion}

Polyethylene/MMT nanocomposite was prepared after modification of MMT clay using Dimethyl di(hydrogenated tallow) ammonium chloride modifier and the modification has been confirmed by XRD and SEM analysis. The prepared nanocomposite was characterized using SEM, FTIR and TGA analysis which confirm the successful preparation of the PPET/ MMT nanocomposite. Pure PET and PET/MMT nanocomposite fibers were produced using melt spinning technique and the prepared fibers were characterized using SEM and FTIR analysis which confirm the successful intercalation of MMT addition PET fiber. PET/MMT filaments have been successfully modified via grafting of MAA monomer onto the PET/MMT filaments been modified by grafting yield of MAA monomer using AIBN initiator under several grafting variable conditions where grafting yield percentage reached maximum value when $3 \%$ of monomer concentration with $4 / 10^{-2}$ gm of AIBN initiator have been used for $120 \mathrm{~min}$ grafting time under temperature $80^{\circ} \mathrm{C}$. The grafting process has been confirmed by SEM and FTIR analysis. The grafting modified PET/MMT filaments have been used in the water treatment process by applied the grafted modified sample in removing of RB 19 cationic dye from its solution under several conditions of $\mathrm{pH}$ value, dye concentration and removal temperature, the results shows that, the dye removal is $\mathrm{pH}$ dependent and reached maximum removal at $\mathrm{pH} 10$ when using $50 \mathrm{mg} / \mathrm{l}$ from dye concentration under $40^{\circ} \mathrm{C}$. 


\section{References}

1. K. M. Hassan and M. Cakmak, Polym. Eng. \& Sci, 57, 550 (2016).

2. G. Chen, W. Geng and L. Zhang, ACS Applied Nano Mater. 1, 6444 (2018).

3. M. Hanifzadeh, M. H. Sarrafzadeh, Z. Nabati, O. Tavakoli, H. Feyzizarnagh, J. Environ. Chem. Eng. 6, 866 (2018)

4. J. Wang, W. Cheng, Y. Gao, L. Zhu, L. Pei, Polymers 11,520 (2019)

5. S. Zekriardehani, A. S. Joshi, S. A. Jabarin, D. W. Gidley, M. R. Coleman, Macromolec. 51, 456 (2018).

6. Q. Zhang, R. Zhang, L. Meng, Y. Lin, X. Chen, X. Li, W. Zhang, L. Li, Polym. 101, 15 (2015).

7. K. Majdzadeh-Ardakani, S. Zekriardehani, M. R. Coleman, S. A. Jabarin, Int. J. Polym. Sci. 2017, 1(2017).

8. R. Reza, E. P. Nguyen, M. D. Kowal, W. H. Mak, S. Rasel, M. A. Islam, A. Abdelaal, A. S. Joshi, S. Zekriardehani, M. R. Coleman, R. B. Kaner, $A d v$. Mater. 30, 1800200 (2018).

9. M. Angelo Miranda, S. A. Jabarin, M. Coleman, J. Appl. Polym. Sci. 134, 45023 (2017).

10. G. Vaseghi, A. Ghassemi, J. Loya, Desalin. Water Treat. 57, 23461 (2016).

11. R. P. Choudhury, J. S. Lee, R. M. Kriegel, W. J. Koros, H. W. Beckham, Macromole. 45, 879, (2012).

12. M. K. Hassan, M. Cakmak, Macromolec. 48, 4657 (2015).

13. A. N. Blaznov, E. V. Atyasova, I. K. Shundrina and A. S. Zubkof, Polym. Test. 60, 49 (2017).

14. C. Silvestre, M. Pezzuto, D. Duraccio, G. R. Mitchell and S. Cimmino, Polym. Bull., 74, 145 (2017).

15. A. M. Slavutsky and M. A. Bertuzzi, Appl. Clay Sci.108, 144 (2015).

16- S. Filip, M.G. Armando, L.G. Gerorgy and G.P Manuel, Energy Fuels 31 (2), 1650 (2017).

17. A. Abdel-Bary, M. A. EL-Nabarawi, D. H. Hassen and A. A. Taha, Int. J. Phar. \& Pharm. Sci., 6, 193 (2014).
18. J. Lai, W. Lin, P. Scholes and M.Li, Mater., 150, 10 (2017).

19. J. Verrey, M.D. Wakeman, V. Michaud, Manson, J.A.E., 37, 9 (2006).

20. D. ASIM, Ind. J. of Fib. \& Text. Res. (IJFTR), 42, 139 (2017).

21. G. S. El-Bahy; Y. M. Abbas; Abdelhamid Hezma; N. M. Gweily, J. Tex. Colour. \& Polym. Sci. 16 (2), 95 (2019).

22. G. S. El-Feky, S. S. Sharaf, A. El Shafei, and A. A. Hegazy, Carbohyd. Polym.158, 11 (2017).

23. D. J. Lee and S. Lee and I. W. Kim, Int. J. Mol. Sci. 13, 10296 (2012).

24. N. H. Anderson, M. Bauer, N. Boussac, R. KhanMalek, P. Munden and M. Sardaro, J. Pharm. Biomed. Anal. 17, 811 (1998). 


\section{مخاليط نانونية من ألياف نانوية مركبة مبنية علي البولي ايثيلين تيريفثالات للمعالجة البيئية \\ رائدة العطاوي \\ قسم الكيمياء ، كلية العلوم ، جامعة تبوك ، تبوك ، 71421 ، المملكة العربية السعودية}

تم تحضير مركبات النانو من الطين البولي إثيلين تيرفثاليت Montmorillonite / بعد تعديل طين Montmorillonite (MMT)

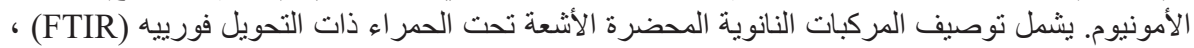

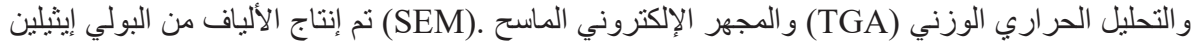

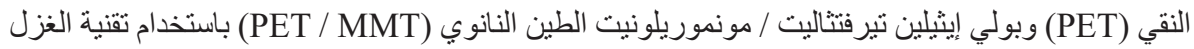

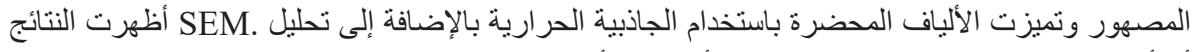

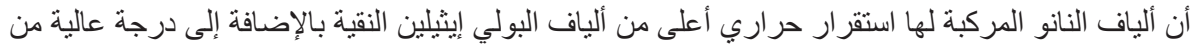

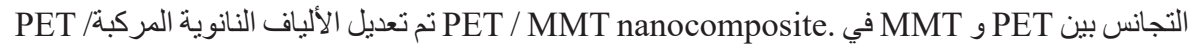

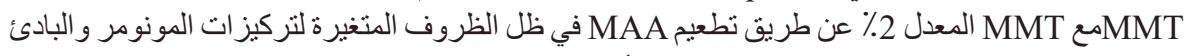

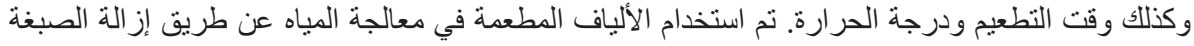

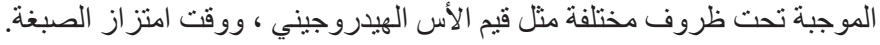

